\title{
Non-lonizing Radiation (NIR) Exposure Map Development Using GIS for Gong Badak, Terengganu, Malaysia
}

\author{
S.N. Hazmin ${ }^{1,2}$, A.R.S.N. Dianah ${ }^{1}$, M.K.A. Kamarudin ${ }^{3}$, R. Umar ${ }^{3}{ }^{*}$, and H.N. Syafiqah ${ }^{3}$, \\ ${ }^{1}$ School of Fundamental Science, Universiti Malaysia Terengganu, 21030, Kuala Nerus, Terengganu, \\ Malaysia \\ ${ }^{2}$ Pusat Islam Sultan Mahmud, Universiti Malaysia Terengganu, 21030, Kuala Nerus, Terengganu, \\ Malaysia \\ ${ }^{3}$ East Coast Environmental Research Institute, Universiti Sultan Zainal Abidin, Gong Badak Campus, \\ 21300, Kuala Nerus, Terengganu, Malaysia
}

\begin{abstract}
Public Non-Ionizing Radiation (NIR) exposure should be monitored by the government since it has proven harmful for human. Even though some studies reported that low frequency spectrum is safe, the other says that long and repetitive exposure may affect health. Thus, this study is conducted to measure the ambient NIR exposure value in the selected Terengganu area, Malaysia. The values were then used to develop a spatial model of exposure to see the radiation exposure pattern. From the findings, we found that the value was higher nearby base stations which are normally erected around residential area where the telecommunication network user is high. Thus, this study is crucial to determine the level of exposure for future plan. This findings can be used by the government to control the radiofrequency transmission and active spectrum service provider in order to limit the radiation exposure for public health concern.
\end{abstract}

\section{Introduction}

Non-Ionizing Radiation (NIR) has been proven may cause adverse health effect by numerous studies [1], Some finding shows that most of people who highly exposed to radio frequency has higher chance to diagnose to have brain tumor and affect the reproductive system other than mild pain such as headaches, insomnia, dizziness and dermatitis [2]. From the study done by Urbinello et al. (2014), they found the arithmetic mean values for mobile phone base station exposure at Basel, Brussels and Amsterdam were far below the international reference level proposed by ICNIRP (International Commision on Non-Ionizing Radiation Protection)[3]. They further their study on the temporal trends of RF-EMF exposure levels in different microenvironment of three European cities (Basel (Switzerland), Ghent and Brussel (Belgium)) and found that an increase of RF-EMF exposure levels has been observed between April 2011 and March 2012. They suggested a continuous monitoring is needed to identify high exposure areas and to anticipate critical development of RF-EMF exposure at public places [4]. 
In this study, the focus will be on the measurement of ambient NIR exposure value in the vicinity of Gong Badak which is located in the district of Kuala Nerus, Terenganu state of Malaysia. This research findings will provide the map of NIR exposure for future monitoring actions. This is essential to make sure the recommended public exposure value by International Radiation Protection Association (IRPA) is complied.

The stakeholders such as telecommunication service provider, internet service provider, radio \& TV broadcasting and other active spectrum user may also benefited from the map to manage the location of their base stations and transmitter for better coverage. The Ministry of Health will be assisted with the management of exposure value limit which is crucial to provide healthy environment to the community. This is due to the fact that overdose nonionizing radiations are proved may cause long term effect to human body \& systems, and also bad for health. The most important thing, this research outcome will propose the Malaysia government, a policy on electromagnetic radiation. This will control the radiofrequency transmission and active spectrum service provider in order to limit the radiation exposure for public health concern.

\section{Methodology}

The step-by-step methodology is as illustrated in Figure 1 below.
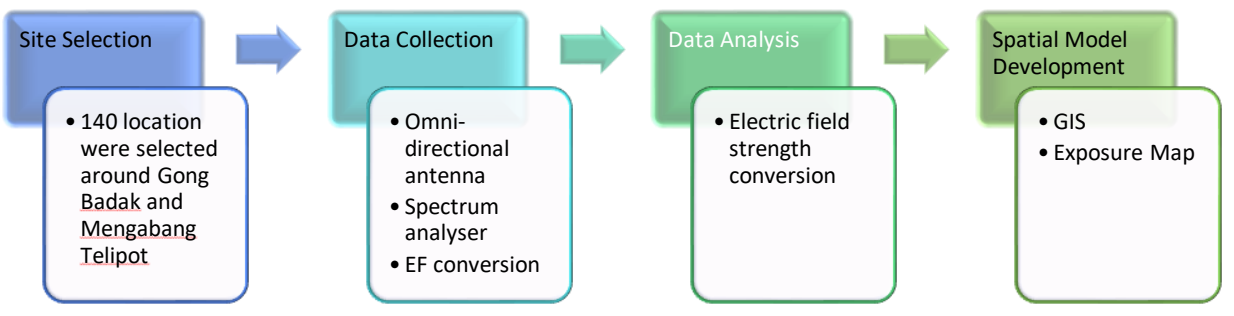

Fig. 1. Flow of the study

\subsection{Site selection}

140 location has been selected around Gong Badak. The data collection sites is determined based on accessibility and the presence of base station tower (BST).

\subsection{Data collection}

In this stage, measurements were conducted using the fabricated antenna specifically for this study, connected to spectrum analyser at selected sites. The signal were recorded for 10 minutes at each selected point roughly from 10.00 am until $4.00 \mathrm{pm}$. Based on the ICNIRP postulate, the temporal average value of exposure over any 6 minutes interval must be used for the comparison with the reference levels suggested [5]. In this study, frequencies below $3 \mathrm{GHz}$ were focussed since daily human activities on spectrum use lies between this range as permitted and allocated by Malaysian Communications and Multimedia Commission (MCMC). 


\subsection{Data analysis}

The raw data was in the form of signal power level value which are in the unit of decibels relative to one millivolt $(\mathrm{dBm} V)$. These data were converted to electric field (EF) strength value where the unit is volt per meter $(\mathrm{V} / \mathrm{m})$. For each site, the maximum exposure value and the average value were obtained. This values were compared with the international reference level proposed by ICNIRP and then used for the exposure value mapping in the next stage.

\subsection{Spatial model development}

The map of ambient exposure level of Gong Badak were developed based on maximum value. The spatial model (map) were developed using ARCGIS software. Interpolation method was used in this study. It is a mathematical technique that enables estimating the values of a curve at any position between known points. Inverse Distance Weighting (IDW) techniques were employed to interpolate the datasets. IDW implements an algorithm that effectively deals with highly variable data during interpolation. This technique computes the value at each assigned grid node by considering the surrounding data points which are between the user-defined radiuses. The most influence factor contribute to the exposure level were determined.

\section{Result and Discussion}

From the measurement, 70 points of ambient NIR exposure value in term of EF strength were collected around Gong Badak. The EF strength at ten points were collected for each sites as shown in Table 1. The shaded cell indicate the highest value recorded for each site.

Table 1. Electric field strength value for each site.

\begin{tabular}{|c|c|c|c|c|c|c|c|}
\hline Sites & $\begin{array}{c}\text { Kubang } \\
\text { Badak }\end{array}$ & UMT & $\begin{array}{c}\text { Gong } \\
\text { Badak }\end{array}$ & Kg. Jati & UniSZA1 & UniSZA2 & $\begin{array}{c}\text { Kg. } \\
\text { Pak } \\
\text { Tuyu }\end{array}$ \\
\hline Population & High & High & Moderate & Moderate & Low & Moderate & Low \\
\hline Point 1 & 5.06 & 3.54 & 11.06 & 0.02 & 4.09 & 10.97 & 3.84 \\
\hline Point 2 & 10.91 & 2.34 & 11.09 & 3.02 & 5.73 & 8.73 & 8.76 \\
\hline Point 3 & 37.82 & 11.42 & 12.77 & 14.63 & 5.24 & 14.63 & 4.05 \\
\hline Point 4 & 9.47 & 34.74 & 11.23 & 12.69 & 8.33 & 7.15 & 9.46 \\
\hline Point 5 & 6.57 & 12.04 & 22.35 & 5.08 & 9.79 & 4.36 & 11.04 \\
\hline Point 6 & 2.03 & 12.12 & 6.50 & 5.23 & 10.14 & 7.89 & 0.22 \\
\hline Point 7 & 3.30 & 2.31 & 3.87 & 10.09 & 11.13 & 0.08 & 0.96 \\
\hline Point 8 & 12.12 & 2.03 & 7.65 & 13.46 & 10.45 & 1.37 & 3.21 \\
\hline Point 9 & 0.64 & 6.57 & 7.63 & 0.08 & 5.48 & 4.30 & 1.19 \\
\hline Point 10 & 34.74 & 8.33 & 13.68 & 15.04 & 5.26 & 3.07 & 2.79 \\
\hline
\end{tabular}

The maximum value obtained from the table were then used to develop a spatial model using interpolation method in ARCGIS. This map illustrates the pattern of exposure at surrounding of the study area as shown in Figure 2. 


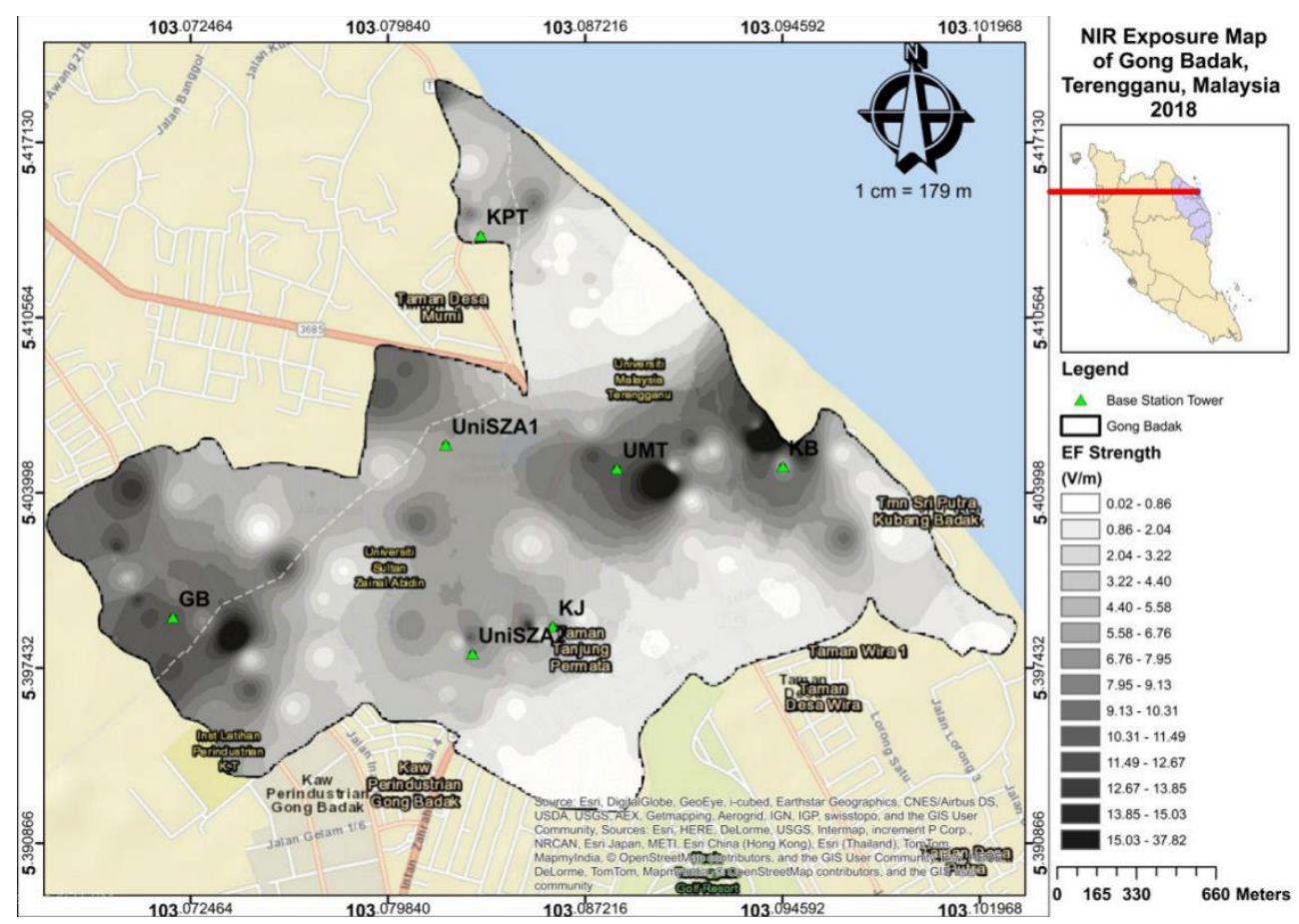

Fig. 2. Spatial model of NIR exposure value at Gong Badak

From the spatial model, we can see the darker area which indicates the higher exposure value were mostly located nearby BST (small triangle). The farther the distance from BST, the lighter the colour, which means the lower the exposure value. However, Kampung Pak Tuyu (KPT) recorded lower exposure value compared with other sites even there is BST nearby. This may because of less resident living in the neighbourhood, contribute to the less data traffic in the area. RF exposure is proved varies on a population basis, where high populated area shows an increasing trend compared to low dense area [6].

Base on Table 1, Kubang Badak has the highest exposure with $37.82 \mathrm{~V} / \mathrm{m}$, followed by UMT with EF strength of $34.74 \mathrm{~V} / \mathrm{m}$. Kubang Badak is close to UMT hostel where the mobile phone user are high. This is the reason why Kubang Badak recorded high exposure value compared to other sites. Moreover, the number of BST nearby will increase the propagation of multipath, thus, easier the interaction between them to occur. This interaction can be divided into two: constructive interferences and destructive interferences [7-8]. The constructive interference occurs when two signal with the same wavelength that propagates aligned with each other and resulted the larger amplitude. Meanwhile, the destructive interference occurs when the two signal were not perfectly aligned or shifted then may resulted the smaller amplitude or no signal at all [9-10]. Therefore, can affect the quality of communication and then, it reduce the exposure [11-12]. Further study on NIR exposure at other location on population basis should be done to investigate the trend and the effect on human for health monitoring purposes.

\section{Conclusion}

NIR exposure value in term of EF strength were measured around Gong Badak, Terengganu, Malaysia to visualize the exposure pattern in the area of concern. From the findings, it can be concluded that the highest EF strength is recorded at Kubang Badak and 
UMT where the data traffic is high due to high population in the neighbourhood where there is located UMT's student hostel. Since NIR exposure has proven can cause adverse health effect, the study on this kind of exposure is crucial for future health concern.

This study is made possible by the usage of grant FRGS/1/2015/SG02/UNISZA/02/1, TPM/68006/2016/79 and UMT 68006/INSENTIF/60. Our sincere gratitude for all assistance and help from Assoc. Prof Dr. Ahmad Nazri b Dagang and Dr. Hajar Ja'far. The authors also thank to Universiti Malaysia Terengganu, Universiti Sultan Zainal Abidin and Universiti Teknologi MARA for the facilities provided.

\section{References}

1. Fatin Syaza Syariff Khan, Roslan Umar, Nor Hazmin Sabri, Mohd Khairul Amri Kamarudin, Azmi Hassan, Hafizan Juahir. Journal of Fundamental and Applied Sciences, 9(2S), 308-316. (2017)

2. Dianah review Siti Nur Dianah Abdul Rahman, Nor Hazmin Sabri, Roslan Umar, Mohd Khairul Amri Kamarudin, Ahmad Nazri Dagang. Journal of Fundamental and Applied Sciences, 9(2S), 182-198. (2017)

3. Damiano Urbinello, Wout Joseph, Anke Huss, Leen Verloock, Johan Beekhuizen, Roel Vermeulen, Luc Martens and Martin Roosl. 2014. Environment International 68. pp4954. (2014)

4. Damiano Urbinello, Wout Joseph, Leen Verloock, Luc Martens and Martin Roosl. Environmental Research 134, pp134-142 (2014)

5. ICNIRP, International Commission on Non-Ionizing Radiation Protection 1998 Guidelines for limiting exposure to time varying electric, magnetic, and electromagnetic fields (up to $300 \mathrm{GHz}$ ), Health Physics, 74 (4) pp 494-522.(1998)

6. Jean-François Viel, Elisabeth Cardis, Monika Moissonnier, René de Seze, Martine Hours 2009 Environment International 35 pp 1150-1154 (2009)

7. Rappaport T S. Wireless Communications Principles and Practice 2nd ed. (Singapore: Pearson Education, Inc.) (2002)

8. Haykin S and Moher M Modern Wireless Communications (Singapore: Pearson Education, Inc.) (2002)

9. Mark J W and Zhuang W. Wireless Communications and Networking (New Delhi: PHI) (2005)

10. Feher K Wireless Digital Communications Modulation and Spread Spectrum Applications (Upper Saddle River, NJ: Prentice Hall) (1995)

11. Blake R Wireless Communications Technology (Delmar, Singapore: Thomson Asia Pvt Ltd) (2004)

12. Agarwal D P and Zeng Q A Introduction to Wireless and Mobile Systems (Nelson, India: Thomson Learning) (2007) 